CARDIOLOGY

\title{
The Prognostic Value of High-Sensitive Troponin I in Stable Coronary Artery Disease Depends on Age and Other Clinical Variables
}

\author{
Rocío Carda e Álvaro Aceña ${ }^{\mathrm{e}}$ Ana Pello $^{\mathrm{e}}$ Carmen Cristóbal $^{\mathrm{a}, \mathrm{b}}$ \\ Nieves Tarín ${ }^{c}$ Ana Huelmos ${ }^{d}$ Joaquín Alonso ${ }^{a, b}$ Dolores Asensio ${ }^{f}$ \\ Óscar Lorenzo ${ }^{g, h}$ José Luis Martín-Venturag, h Luis Blanco-Coliog \\ Jerónimo Farrée, h Lorenzo López Bescós ${ }^{b} \quad$ Jesús Egido ${ }^{g-i} \quad$ José Tuñón ${ }^{\mathrm{e}}{ }^{\mathrm{g}} \mathrm{h}$ \\ ${ }^{a}$ Department of Cardiology, Hospital de Fuenlabrada, ${ }^{b}$ Rey Juan Carlos University, ${ }^{c}$ Department of Cardiology, \\ Hospital Universitario de Móstoles, ${ }^{d}$ Department of Cardiology, Hospital Universitario Fundación Alcorcón, \\ Departments of ${ }^{\mathrm{e}}$ Cardiology and ${ }^{\mathrm{f}}$ Biochemistry and ${ }^{\mathrm{g}}$ Laboratory of Vascular Pathology, IIS-Fundación Jiménez Díaz, \\ hAutónoma University, and 'CIBERDEM, Madrid, Spain
}

\section{Key Words}

Stable coronary artery disease $\cdot$ Prognosis $\cdot$ High-sensitive troponin · Biomarkers

\section{Abstract \\ Objectives: To study the prognostic value of high-sensitive troponin (hs-cTn) I in stable coronary artery disease. Meth- ods: In total, we studied 705 patients. Secondary outcomes were the incidence of: (1) acute ischemic events and (2) heart failure or death. The primary outcome was the composite of them. Results: Patients with hs-cTnl >0 ng/ml (62.1\%) were older, had a lower estimated glomerular filtration rate, more frequent a history of hypertension, atrial fibrillation, ejection fraction $<40 \%$, and therapy with angiotensin-converting en- zyme inhibitors, diuretics and acenocumarol. The follow-up period was $2.2 \pm 0.99$ years. Fifty-three patients suffered an acute ischemic event, 33 died or suffered heart failure and 78 developed the primary outcome. By univariate Cox's regres- sion analysis, hs-cTnl $>0$ was associated with a higher risk of developing the primary outcome [relative risk $=2.360$ (1.359-4.099); $p=0.001$ ] and heart failure or death [relative}

risk $=5.932$ (1.806-19.482); $p<0.001]$, but not with acute ischemic events. Statistical significance was lost after controlling for age. By logistic regression analysis, age [relative risk $=1.026(1.009-1.044) ; p=0.003$ ], ejection fraction $<40 \%$ [relative risk $=4.099(2.043-8.224) ; p<0.001$ ], use of anticoagulants [relative risk $=2.785(1.049-7.395) ; p=0.040$ ] and therapy with angiotensin-converting enzyme inhibitors [relative risk $=1.471(1.064-2.034) ; \mathrm{p}=0.020 \mathrm{]}$, and estimated glomerular filtration rate [relative risk $=0.988$ (0.977-0.999); $\mathrm{p}=0.027]$ were associated with $\mathrm{hs}-\mathrm{cTnl}>0$. Conclusions: In stable coronary disease, hs-cTnl is associated with the incidence of heart failure or death, but this relationship depends on other variables.

(c) 2015 S. Karger AG, Basel

\section{Introduction}

The new high-sensitive assays allow more accurate detection of plasma troponin than conventional tests. They determine cardiac troponin concentrations up to 10 times lower and with less analytical imprecision [1,2]. Given

\section{KARGER 125}

(c) 2015 S. Karger AG, Basel

$0008-6312 / 15 / 1321-0001 \$ 39.50 / 0$

E-Mail karger@karger.com

www.karger.com/crd
José Tuñón, MD, PhD

Department of Cardiology, IIS-Fundación Jiménez Díaz

Avenida Reyes Católicos 2

ES-28040 Madrid (Spain)

E-Mail jtunon@secardiologia.es 
that its use is increasing in clinical practice, it is important to understand the clinical significance of the positivity of high-sensitivity cardiac troponin (hs-cTn) in patients with cardiovascular disease.

As conventional troponin, hs-cTn is used for the diagnosis and prognosis of acute coronary syndromes $[3,4]$. However, in recent years it has been suggested that hs-cTn could have prognostic value in several disorders, such as heart failure (HF) [5-7], pulmonary embolism and pulmonary hypertension [8], in patients with cardiovascular risk factors $[9,10]$, in subjects of middle or advanced age [11-13], and in stable coronary artery disease (SCAD) [14, 15]. However, the possible role of hs-cTn in SCAD as a prognostic biomarker is not clear. In addition, we are still far from understanding what causes the elevation of this biomarker in conditions other than acute coronary syndrome. Although hs-cTn is theoretically released only by the myocardium during necrosis, it has been proven that it also rises in other diseases in which it is additionally a death marker [16]. In this work, we studied the prognostic value of hs-cTnI in 705 patients with SCAD.

\section{Materials and Methods}

The research protocol complied with the Helsinki Declaration and was approved by the ethics committees of the participant hospitals. All patients signed informed consent documents. The BACS (Biomarkers in Acute Coronary Syndrome) and BAMI (Biomarkers in Acute Myocardial Infarction) studies included patients admitted at the Fundación Jiménez Díaz, Fuenlabrada, Móstoles and Alcorcón hospitals in Madrid with either non-ST elevation acute coronary syndrome (NSTEACS) or ST-elevation myocardial infarction (STEMI). The inclusion criteria have been previously defined [17]. The exclusion criteria were age over 85 years, the coexistence of other significant cardiac disorders, such as cardiomyopathies, present pericardial disease or valve disease (cases with left ventricular hypertrophy secondary to hypertension, nonsevere valve regurgitation without anatomic abnormalities, and degenerative aortic stenosis with a mean gradient lower than $25 \mathrm{~mm} \mathrm{Hg}$ were allowed to enter the study), the coexistence of any illness or toxic habits that could limit patient survival, impossibility to perform revascularization when indicated, and subjects in whom follow-up was not possible. In order to avoid variability of findings due to an excessive heterogeneity in the intervals between the acute event and blood extraction, the investigators agreed to exclude patients that were not clinically stable at day 6 of the index event.

In addition to plasma withdrawal at discharge, a second plasma sample was extracted between 6 and 12 months later, on an outpatient basis. This paper reports data from the clinical and analytic findings obtained at this second plasma extraction, relating them to subsequent follow-up.

Between July 2006 and April 2010, 1,898 patients were discharged from the hospitals of the study with a diagnosis of NSTEACS or STEMI. Eight hundred and thirty-eight patients were included in the study. The remaining patients were not included due to the following: age over 85 years $(17.3 \%)$, presence of disorders or toxic habits limiting survival (29.0\%), impossibility to perform cardiac revascularization (14.5\%), coexistence of another significant cardiac disorder (6.8\%), impossibility to perform follow-up (12.0\%), clinical instability beyond the 6th day at the index event (9.1\%), refusal to participate in the study (2.0\%), and impossibility of the investigators to include them because of holiday periods (9.3\%). Of the 838 patients included, 7 died before the second visit, and 710 had available adequate plasma samples at that time. This visit took place between January 2007 and February 2011. The final follow-up visits took place in May 2012.

\section{Study Design}

At baseline, a complete set of clinical variables of the patients was recorded and 12-hour fasting venous blood samples were withdrawn and collected in EDTA. Blood samples were centrifuged at $2,500 \mathrm{~g}$ for $10 \mathrm{~min}$ and plasma was stored at $-80^{\circ} \mathrm{C}$. Patients were seen every year at their hospital. At the end of follow-up (maximum 4.6 years) the medical records were reviewed and patient status was confirmed by telephone contact.

The secondary outcomes were: (1) recurrence of acute ischemic events, such as NSTEACS, STEMI, stroke or transient ischemic attack, and (2) incidence of HF or death. The primary outcome was the composite of the secondary end points.

NSTEACS was defined as rest angina lasting for more than 20 $\mathrm{min}$ in the previous $24 \mathrm{~h}$, or new-onset class III-IV angina, along with transient ST depression or T wave inversion in the electrocardiogram considered diagnostic by the attending cardiologist and/ or conventional troponin elevation. STEMI was defined as symptoms compatible with angina lasting for more than $20 \mathrm{~min}$ and ST elevation in 2 adjacent leads in the electrocardiogram without response to nitroglycerin, and troponin elevation. A past myocardial infarction was diagnosed when new pathological Q waves were present in the electrocardiogram along with a new myocardial scar identified either by echocardiography or nuclear magnetic resonance imaging in the same myocardial region. Stroke was defined as the rapid onset of a persistent neurological deficit attributable to a focal vascular cause lasting for more than $24 \mathrm{~h}$, or of less duration if imaging studies reported the presence of new ischemic lesions. A transient ischemic attack was defined as a transient stroke with signs and symptoms resolving before $24 \mathrm{~h}$, without new ischemic lesions in imaging studies. Events were adjudicated by at least 2 investigators of the study, along with a neurologist for cerebrovascular events.

\section{Analytical Studies}

Laboratory analyses were carried out at the Clinical Biochemistry Laboratory at the IIS-Fundación Jiménez Díaz by investigators who were unaware of the clinical data. Hs-cTnI was assessed by direct chemiluminescence (ADVIA Centaur; Siemens, Berlin, Germany), and high-sensitivity C-reactive protein was determined by latex-enhanced immunoturbidimetry (ADVIA 2400 Chemistry System; Siemens). Lipids, glucose and creatinine determinations were carried out by standard methods (ADVIA 2400 Chemistry System).

\section{Statistical Analysis}

Quantitative data that followed a normal distribution are presented as the mean \pm standard deviation and compared using the 
Student $t$ test. Those not normally distributed are displayed as the median with interquartile range and compared using the MannWhitney test. Qualitative variables are displayed as percentages and were compared by $\chi^{2}$ or Fisher's exact test when appropriate. Cox's proportional hazards model was performed with forward, stepwise selection to assess the variables associated with the primary and the secondary outcomes. Variables with $\mathrm{p}<0.05$ were entered into the model, and those with $\mathrm{p}>0.10$ were removed. In model 1, the risk of events was estimated according solely to the values of hs-cTnI. In model 2, risk was adjusted for age and sex. Finally, in model 3, the following clinical, analytical and treatment variables were added: diabetes, smoking status, hypertension, body mass index, lipid levels; previous history of peripheral artery disease, cerebrovascular events, atrial fibrillation; ejection fraction $<40 \%$, glomerular filtration rate (GFR) assessed by the chronic kidney disease epidemiology collaboration method (CKD-EPI); highsensitivity C-reactive protein; therapy with aspirin, clopidogrel, statins, acenocumarol, angiotensin-converting enzyme inhibitors, angiotensin receptor blockers, $\beta$-blockers, nitrates/nitroglycerin and diuretics; the type of the most recent acute coronary event, the number of diseased vessels and existence of complete revascularization at that event. Kaplan-Meier curves and log-rank test were used to compare time to outcome according to a multimarker score. A two-sided $\mathrm{p}<0.05$ was considered significant. Analyses were performed with SPSS 19.0 (SPSS Inc., New York, N.Y., USA).

\section{Results}

Five patients were lost to follow-up, so the study population was finally made up of 705 patients. Hs-cTnI was $>0 \mathrm{ng} / \mathrm{ml}$ in $62.1 \%$ of cases, with median and maximal values of $0.008(0.003-0.017)$ and $3.446 \mathrm{ng} / \mathrm{ml}$, respectively. Cases with hs-cTnI $>0$ were older, had a lower GFR, a more frequent history of hypertension, atrial fibrillation, left ventricular ejection fraction $<40 \%$ and therapy with angiotensin-converting enzyme inhibitors, diuretics and acenocumarol than those with hs-cTnI $=0$, with no significant differences in the other variables at univariate analysis (table 1). The follow-up period was 2.2 \pm 0.99 years.

Fifty-three patients developed acute ischemic events: there were 4 STEMI, 22 NSTEACS, 17 cases of unstable angina, 8 strokes and 10 transient ischemic attacks. Four patients suffered 2 events and 2 patients experienced 3 events.

Thirty-three patients developed the secondary outcome of $\mathrm{HF}$ or death. There were 16 episodes of $\mathrm{HF}$ and 23 deaths, with 6 patients suffering both events. Nine deaths were due to cardiovascular causes and 4 to malignancies. Infection, renal failure, bowel ischemia, gastrointestinal bleeding and pancreatitis each accounted for 1 death. Five deaths were of unknown etiology. Of the 9 cardiovascular deaths, 4 were due to $\mathrm{HF}, 3$ were sudden deaths, 1 was due to NSTEACS with HF and 1 was due to NSTEACS alone. Ultimately, 78 patients developed the primary outcome.

Hs-cTnI was more frequently positive in patients who developed the primary outcome (79.5 vs. $60.0 \%$; p < 0.001 ) and HF or death (90.6 vs. $60.8 \%$; p < 0.001$)$. Nevertheless, there was not a significant association with the occurrence of acute ischemic events (73.6 vs. $61.2 \%$; $\mathrm{p}=$ 0.079).

The concentration of hs-cTnI was higher in patients who developed the primary outcome $[0.010(0.001-0.025)$ vs. $0.002(0.000-0.009) \mathrm{ng} / \mathrm{ml} ; \mathrm{p}<0.001]$ and the composite end point of death and HF $[0.023(0.007-0.047)$ vs. $0.002(0.000-0.010) \mathrm{ng} / \mathrm{ml} ; \mathrm{p}<0.001]$ than in those who remained stable. Here again, these differences were not significant for the development of acute ischemic events $(0.056 \pm 0.247$ vs. $0.154 \pm 3.566 \mathrm{ng} / \mathrm{ml} ; \mathrm{p}=0.841)$.

Kaplan-Meier curves showed that patients with hscTnI $>0$ were more likely to develop the primary outcome (fig. 1a) and HF or death (fig. 1b), but not acute ischemic events (fig. 1c). By Cox's regression, in the univariate analysis (table 2 , model 1 ), hs-cTnI $>0$ was associated with a higher risk of developing the primary outcome. However, when controlling for age (model 2) and for the other variables described previously (model 3), the statistical significance was lost. The results were similar when we analyzed the risk of HF or death during the follow-up (table 3, models 1-3) and did not vary if these two events were analyzed separately (not shown). Finally, hs-cTnI $>0$ was not associated with the recurrence of acute ischemic events in the univariate analysis (not shown). By logistic regression analysis, from all the variables described in table 1 that were significantly different in the groups with hs-cTnI $>0$ and hs-cTnI $=0$, only age, left ventricular ejection fraction $<40 \%$, treatment with acenocumarol and GFR were significantly associated with the hs-cTnI $>0$ group (table 4 ).

\section{Discussion}

Coronary artery disease is highly prevalent. In a recent cross-sectional study in Spain, $4.9 \%$ of the population older than 40 years had this diagnosis [18]. There are several clinical risk scores to predict outcomes in patients with acute coronary syndromes, such as the TIMI risk score [19] and the GRACE score [20]. In addition to clinical variables, troponin plasma levels are included in these scores. However, with the exception of lipid levels, no risk score or biomarker has been unanimously accepted for 
Table 1. Characteristics of patients with and without elevated hs-cTnI

\begin{tabular}{|c|c|c|c|}
\hline & $\begin{array}{l}\text { Patients with } \\
\text { hs-cTnI }=0\end{array}$ & $\begin{array}{l}\text { Patients with } \\
\text { hs-cTnI }>0\end{array}$ & $\mathrm{p}$ \\
\hline \multicolumn{4}{|l|}{ Clinical data } \\
\hline Age, years & $56.0(50.0-65.0)$ & $64.0(55.0-74.0)$ & $<0.001^{*}$ \\
\hline Male sex, \% & 71.5 & 77.4 & 0.088 \\
\hline Caucasian race, $\%$ & 96.2 & 97.5 & 0.367 \\
\hline Body mass index & $28.6 \pm 4.3$ & $28.8 \pm 4.7$ & 0.577 \\
\hline Diabetes mellitus, \% & 21.3 & 24.4 & 0.360 \\
\hline Present smoker, \% & 7.5 & 5.9 & 0.435 \\
\hline Hypertension, \% & 57.3 & 69.9 & $0.001^{*}$ \\
\hline Peripheral artery disease, $\%$ & 2.6 & 4.6 & 0.228 \\
\hline Cerebrovascular events, \% & 1.9 & 4.3 & 0.089 \\
\hline Previous CABG, $\%$ & 6.4 & 9.6 & 0.161 \\
\hline Previous PCI, \% & 74.5 & 80.4 & 0.075 \\
\hline Atrial fibrillation, $\%$ & 1.9 & 7.1 & $0.002^{*}$ \\
\hline Ejection fraction $<40 \%, \%$ & 3.7 & 16.7 & $<0.001^{*}$ \\
\hline NYHA class & & & $<0.001^{*}$ \\
\hline I & 78.9 & 57.2 & \\
\hline II & 17.5 & 31 & \\
\hline III & 3.6 & 10.7 & \\
\hline IV & 0.0 & 1.1 & \\
\hline \multicolumn{4}{|l|}{ Medical therapy } \\
\hline Aspirin, \% & 92.5 & 91.7 & 0.776 \\
\hline Clopidogrel, \% & 69.7 & 66.4 & 0.407 \\
\hline Acenocumarol, \% & 1.9 & 8.7 & $<0.001^{*}$ \\
\hline Statins, $\%$ & 85.4 & 88.8 & 0.197 \\
\hline ACEI, \% & 49.1 & 58.9 & $0.012^{*}$ \\
\hline $\mathrm{ARB}, \%$ & 15.7 & 16.9 & 0.754 \\
\hline$\beta$-Blockers, $\%$ & 78.3 & 75.1 & 0.362 \\
\hline Nitrates/nitroglycerin, \% & 14.6 & 18.5 & 0.215 \\
\hline Diuretics, $\%$ & 13.1 & 23.5 & $0.001^{*}$ \\
\hline \multicolumn{4}{|l|}{ Data from most recent acute coronary event } \\
\hline STEMI/NSTEACS, \% & $23.6 / 76.4$ & $47.7 / 52.3$ & $<0.001^{*}$ \\
\hline Vessels diseased, $\mathrm{n}$ & $1.30 \pm 0.83$ & $1.42 \pm 0.79$ & $0.048^{*}$ \\
\hline Complete revascularization, $\%$ & 73.4 & 60.5 & $0.002 *$ \\
\hline \multicolumn{4}{|l|}{ Analytical data } \\
\hline LDL cholesterol, mg/dl & $83.1 \pm 23.3$ & $83.2 \pm 27.0$ & 0.947 \\
\hline HDL cholesterol, mg/dl & $44.6 \pm 10.3$ & $43.4 \pm 11.2$ & 0.162 \\
\hline Triglycerides, mg/dl & $128.4 \pm 87.3$ & $132.2 \pm 80.0$ & 0.555 \\
\hline $\mathrm{GFR}, \mathrm{ml} / \mathrm{min} / 1.73 \mathrm{~m}^{2}$ & $81.44(71.27-93.81)$ & $74.34(59.14-86.78)$ & $<0.001^{*}$ \\
\hline High-sensitivity C-reactive protein, mg/l & $1.64(0.68-3.62)$ & $2.23(0.92-4.32)$ & $0.003^{*}$ \\
\hline Troponin, ng/ml & $0.0(0.0-0.0)$ & $0.008(0.003-0.017)$ & $<0.001^{*}$ \\
\hline
\end{tabular}

risk stratification of patients with SCAD. Nevertheless, in the SCAD guidelines of the European Society of Cardiology [21], risk stratification is considered to be an important part of the management of these patients because it identifies those at higher risk who could potentially benefit from a more aggressive therapeutic strategy.

Though the use of cardiac troponins is well established in the management of patients with an acute coronary 

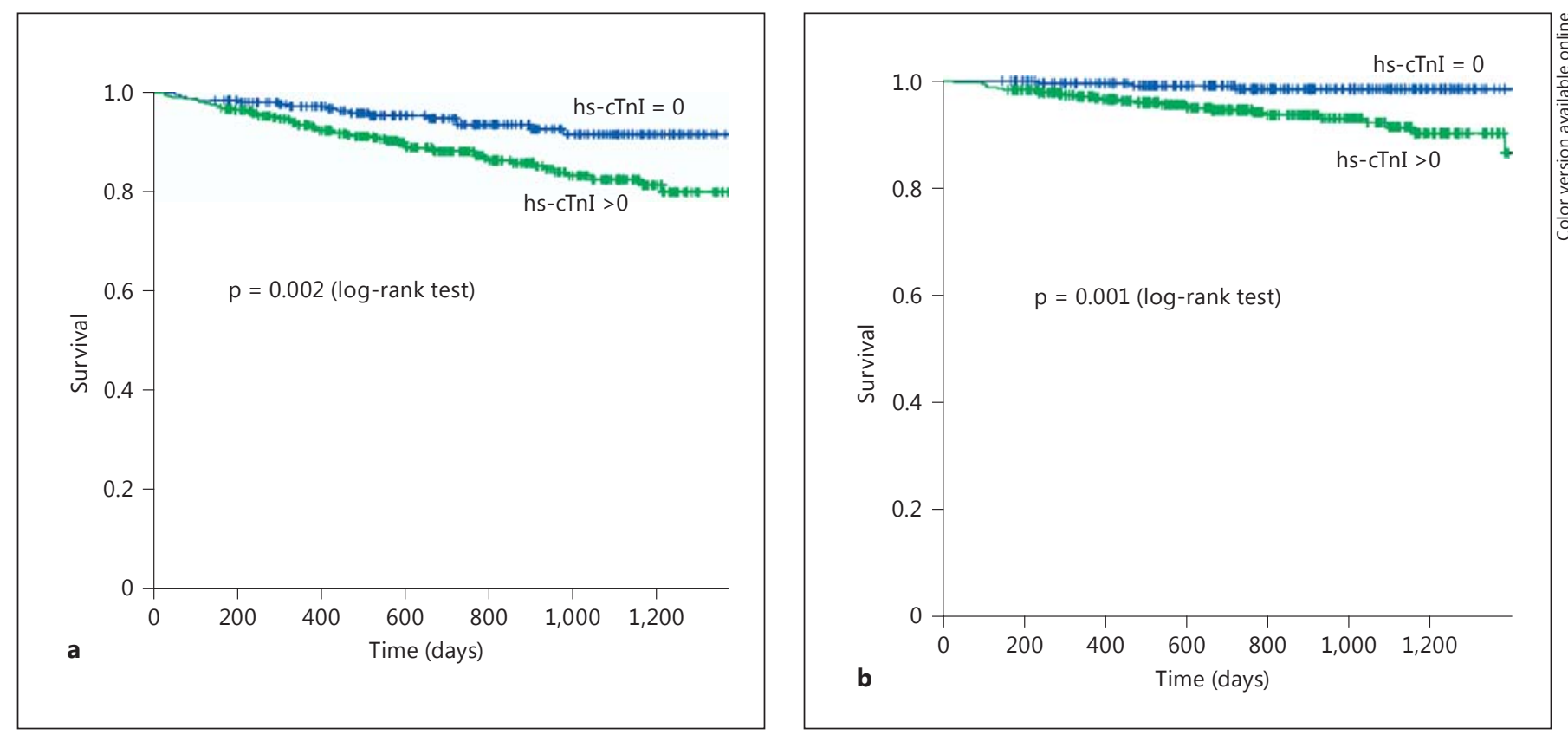

Fig. 1. Kaplan-Meier curves of acute ischemic events, HF or death (a), HF or death (b), and acute ischemic events alone (c) per positivity of hs-cTnI at baseline.

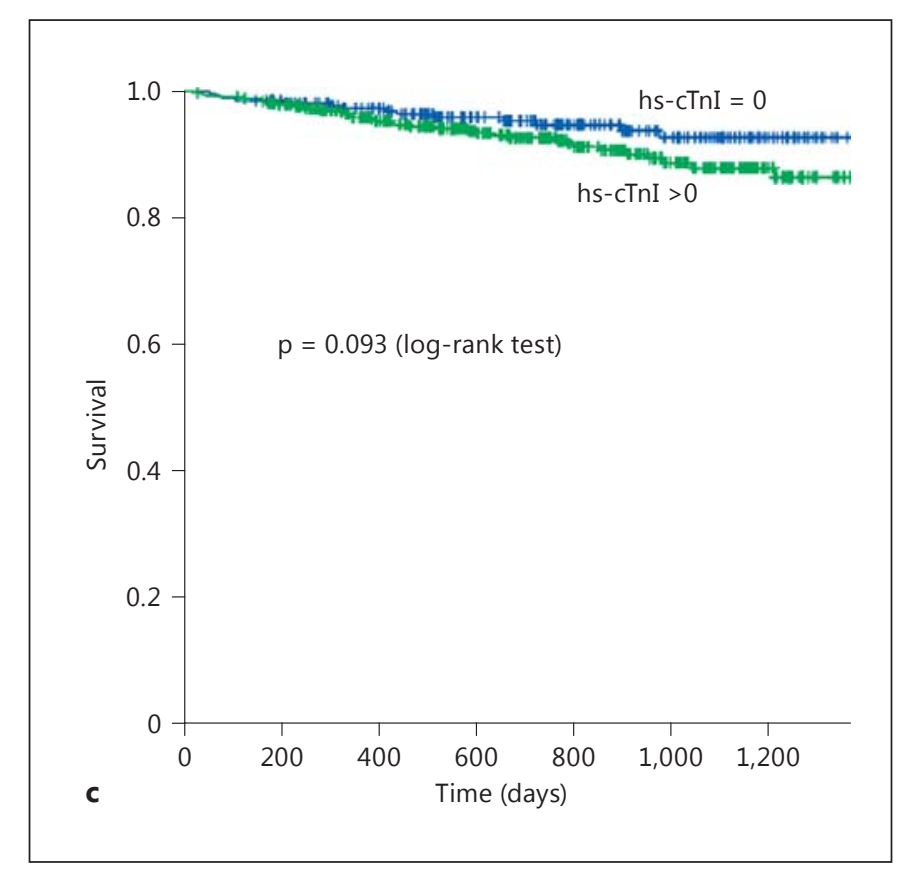

syndrome, it has also been described that plasma troponin levels are increased in $0.7 \%$ of the general population between the ages of 30 and 65 years [22]. Moreover, only $53 \%$ of patients who have troponin elevation on admission receive a main diagnosis of acute coronary syndrome [16]. The other medical conditions of these patients include arrhythmia, sepsis, pulmonary and neurological diseases, and renal failure. Death rates were higher in this

group of patients, suggesting a relationship between elevated troponin levels and an increased noncoronary mortality [16].

The availability of hs-cTn assays allows for a better understanding of the relationship of this biomarker with other diseases. The prevalence of detectable hs-cTnT is $25 \%$ in the population aged between 30 and 65 years [11], $66.5 \%$ in the those aged $54-74$ years [13], and $66.2 \%$ in 
Table 2. Cox's proportional hazards model for the incidence of acute ischemic events, HF or death

\begin{tabular}{|c|c|c|c|c|c|c|c|c|c|}
\hline & \multicolumn{3}{|c|}{ Model 1} & \multicolumn{3}{|c|}{ Model 2} & \multicolumn{3}{|c|}{ Model 3} \\
\hline & HR & $95 \% \mathrm{CI}$ & $\mathrm{p}$ & HR & $95 \% \mathrm{CI}$ & $\mathrm{p}$ & HR & $95 \% \mathrm{CI}$ & $\mathrm{p}$ \\
\hline hs-cTnI & 2.360 & $1.359-4.099$ & 0.002 & & & & & & \\
\hline Age & & & & 1.06 & $1.039-1.081$ & $<0.001$ & 1.03 & $1.002-1.059$ & 0.035 \\
\hline Hypertension & & & & & & & 2.325 & $1.127-4.793$ & 0.022 \\
\hline BMI & & & & & & & 1.071 & $1.017-1.127$ & 0.009 \\
\hline $\mathrm{AF}$ & & & & & & & 2.045 & $1.084-3.858$ & 0.027 \\
\hline GFR & & & & & & & 0.983 & $0.968-0.998$ & 0.031 \\
\hline Nitrates & & & & & & & 2.364 & $1.434-3.899$ & 0.001 \\
\hline
\end{tabular}

Model 1: risk events associated with hs-cTnI. Model 2: risk adjusted for age and sex. Model 3: risk adjusted for variables in model 2 plus diabetes, smoking status, hypertension, body mass index (BMI), low-density lipoprotein, high-density lipoprotein and triglycerides plasma levels, previous history of peripheral artery disease, cerebrovascular events, atrial fibrillation (AF), ejection fraction $<40 \%$, GFR assessed by the CKD-EPI, high-sensitivity
C-reactive protein, therapy with aspirin, clopidogrel, statins, acenocumarol, angiotensin-converting enzyme inhibitors, angiotensin receptor blockers, $\beta$-blockers, nitrates/nitroglycerin and diuretics, type of most recent acute coronary event and number of diseased vessels, and existence of complete revascularization at that event. $\mathrm{HR}=$ Hazard ratio; $\mathrm{CI}=$ confidence interval.

Table 3. Cox's proportional hazards model for the incidence of HF or death

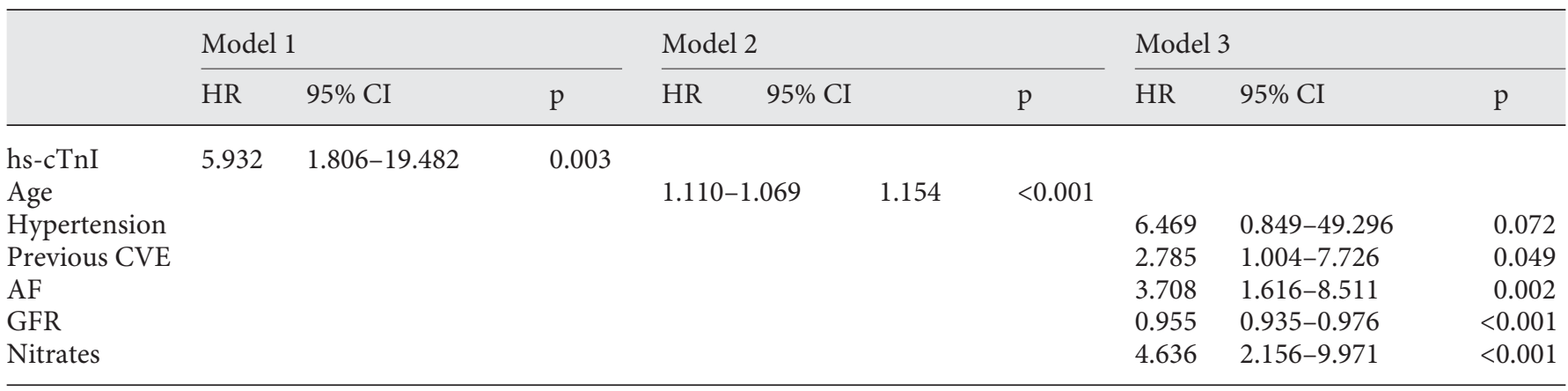

Models 1-3 and abbreviations are as described in table 2 footnote. CVE $=$ Cerebrovascular events.

adults $>65$ years [12]. Concentrations of hs-cTn were higher in men, African Americans and individuals with chronic kidney disease [23]. Hs-cTnT levels have been associated mostly with aging, the presence of traditional cardiovascular risk factors, low estimated GFR, high levels of inflammatory biomarkers [11,24], left ventricular hypertrophy, left ventricular systolic dysfunction, a history of $\mathrm{HF}$, elevated concentrations of brain-type natriuretic peptide, the presence of atrial fibrillation [24, 25], coronary calcification, and soft/mixed plaques in the CT coronary angiography [26]. According to this, increased levels of hs-cTnT have been found in $78 \%$ of ambulatory patients with hypertension and no history of HF, and in $45 \%$ of women with diabetes mellitus $[9,10]$. In our study, we also found a relationship between hs-cTn and a worse clinical profile because patients with detectable concentrations of hs-cTnI had a higher prevalence of hypertension, atrial fibrillation and left ventricular ejection fraction $<40 \%$, more frequent use of diuretics and a lower estimated GFR than those without detectable hs-cTn.

Regarding the prognostic value of hs-cTn, several studies have described associations between increased levels of this biomarker and future risk of HF or death. This connection has been observed in the general population without a history of previous cardiac disease [2,23], in patients with SCAD [14, 15, 27-29] and HF [5-7], and even in patients with pulmonary embolism or pulmonary hypertension [8]. However, there is no consensus on the power of hs-cTn to predict the development of acute ischemic events. Some studies have found this relationship to 
Table 4. Correlates of hs-c $\mathrm{TnI}>0$ by logistic regression analysis

\begin{tabular}{lllc}
\hline Variable & OR & $95 \%$ CI & $\mathrm{p}$ \\
\hline Age & 1.026 & $1.009-1.044$ & 0.003 \\
LVEF $<40 \%$ & 4.099 & $2.043-8.224$ & $<0.001$ \\
Acenocumarol & 2.785 & $1.049-7.395$ & 0.04 \\
ACEI & 1.471 & $1.064-2.034$ & 0.02 \\
GFR & 0.988 & $0.977-0.999$ & 0.027 \\
\hline
\end{tabular}

Constant: relative risk $=0.61 ; \mathrm{p}=0.560 . \mathrm{LVEF}=$ Left ventricular ejection fraction; ACEI = angiotensin-converting enzyme inhibitors; $\mathrm{OR}=$ odds ratio; $\mathrm{CI}=$ confidence interval.

exist, although with less predictive power than for mortality, or appearing in the context of composite outcomes including mortality $[13,24,27]$. Other investigations have shown no statistically significant relationship [28, 29]. Similar findings were observed in our study: at univariate analysis, hs-cTn was associated with the outcome of death, HF or acute ischemic events. However, only the outcome of death or HF was associated with high hs-cTn when a separate analysis was performed as hs-cTn did not predict the isolated risk of acute ischemic events.

The higher sensitivity of hs-cTn comes at the expense of specificity, and this must always be taken into account when interpreting the results in a particular patient. Elevated troponin concentrations are observed in noncardiac diseases, such as stroke, sepsis, adult respiratory distress syndrome, and even after strenuous exercise [30]. The etiology of these minor elevations in patients who do not have an acute coronary syndrome is being investigated because the release, degradation and elimination of this biomarker have not been completely elucidated. Several theories have been suggested for the different conditions, such as increasing oxidative stress and the effect of inflammatory cytokines in $\mathrm{HF}$, decreased clearance in chronic kidney diseases, increased cardiomyocyte apoptosis in the set of increased ventricular load, or coronary microembolisms in patients with nonobstructive coronary disease $[8,31,32]$.

It seems clear that moderate elevations of hs-cTn in conditions other than acute coronary syndrome are associated with comorbidities and any degree of underlying heart disease that causes silent myocardial injury. In our study, the predictive value of hs-cTnI is clearly influenced by these factors (age, sex, low left ventricular ejection fraction, concurrence of atrial fibrillation or chronic kidney disease). Previous investigations have shown an independent relationship between the eleva- tion of the hs-cTn and the risk of events at follow-up [27, 28]. Nevertheless, these findings resulted from clinical trials, where patient selection is influenced by the aims of the trial. Moreover, in these trials, patients were less frequently treated with $\beta$-blockers, statins and drugs acting on the renin-angiotensin system than they are now $[15,27,28]$. Moreover, in some of these studies, patients with left ventricular ejection fraction $<40 \%$ were excluded $[15,28]$. In contrast, our study included patients with low left ventricular ejection fraction, and the treatment they received was in accordance with the recently published guidelines on the management of SCAD [21]. Therefore, the clinical usefulness of this high-sensitive biomarker to assess risk in these patients is controversial. Our conclusions are in agreement with the European Society of Cardiology guidelines on the management of SCAD, which state that although there is some prognostic value associated with the amount of troponin, this value is not sufficient enough to recommend systematic measurement in out-of-hospital patients with SCAD [21].

The limitations of our study include the exclusion of patients with clinical instability in the first days after the index event, as these patients would probably have had a worse prognosis. Nevertheless, only $9 \%$ of cases were excluded for this reason.

\section{Conclusions}

In patients with SCAD, high levels of hs-cTnI are associated with an increased incidence of HF or death. Nevertheless, this association does not have an independent prognostic value and is explained by age and other clinical variables.

\section{Acknowledgements}

We acknowledge the following sources of funding for this study: Fondo de Investigaciones Sanitarias (PI05/0451, PI05/1497, PI0/52475, PI05/1043, PS09/01405, PI10/00234, PI14/1567, and Programa Estabilización to L.B.-C.), Spanish Society of Cardiology, Spanish Heart Foundation, Ministerio de Ciencia e Innovación (SAF 2010/21852), Spanish Society of Arteriosclerosis, Comunidad de Madrid (sGEN/0247/2006), Biobank grants from Instituto de Salud Carlos III FEDER, RD09/0076/00101 (FJD Biobank).

\section{Conflict of Interest}

The authors have no conflicts of interest to declare. 


\section{References}

1 Apple FS, Collinson PO: Analytical characteristics of high-sensitivity cardiac troponin assays. Clin Chem 2012;58:54-61.

2 Jaffe AS, Ordonez-Llanos J: High-sensitivity cardiac troponin: from theory to clinical practice. Rev Esp Cardiol 2013;66:687-691.

-3 Ndrepepa G, Braun S, Mehilli J, Birkmeier KA, Byrne RA, Ott I, Hösl K, Schulz S, Fusaro M, Pache J, Hausleiter J, Laugwitz KL, Massberg S, Seyfarth M, Schömig A, et al: Prognostic value of sensitive troponin $\mathrm{T}$ in patients with stable and unstable angina and undetectable conventional troponin. Am Heart J 2011; 161:68-75.

-4 Thygesen K, Alpert JS, Jaffe AS, Simoons ML, Chaitman BR, White HD: Third universal definition of myocardial infarction. J Am Coll Cardiol 2012;60:1581-1598.

$\checkmark 5$ De Antonio M, Lupon J, Galan A, Vila J, Zamora E, Urrutia A, Díez C, Coll R, Altimir S, Bayes-Genis A: Head-to-head comparison of high-sensitivity troponin $\mathrm{T}$ and sensitivecontemporary troponin I regarding heart failure risk stratification. Clin Chim Acta 2013; 426:18-24.

6 Kociol RD, Pang PS, Gheorghiade M, Fonarow GC, O'Connor CM, Felker GM: Troponin elevation in heart failure prevalence, mechanisms, and clinical implications. J Am Coll Cardiol 2010;56:1071-1078.

7 Latini R, Masson S, Anand IS, Missov E, Carlson M, Vago T, Angelici L, Barlera S, Parrinello G, Maggioni AP, Tognoni G, Cohn JN: Prognostic value of very low plasma concentrations of troponin $\mathrm{T}$ in patients with stable chronic heart failure. Circulation 2007;116:1242-1249.

8 Xu RY, Zhu XF, Yang Y, Ye P: High-sensitive cardiac troponin T. J Geriatr Cardiol 2013;10: 102-109.

9 Everett BM, Cook NR, Magnone MC, Bobadilla M, Kim E, Rifai N, Ridker PM, Pradhan AD: Sensitive cardiac troponin $\mathrm{T}$ assay and the risk of incident cardiovascular disease in women with and without diabetes mellitus: the Women's Health Study. Circulation 2011; 123:2811-2818.

10 Sato Y, Yamamoto E, Sawa T, Toda K, Hara T, Iwasaki T, Fujiwara H, Takatsu Y: Highsensitivity cardiac troponin $\mathrm{T}$ in essential hypertension. J Cardiol 2011;58:226-231.

11 De Lemos JA, Drazner MH, Omland T, Ayers CR, Khera A, Rohatgi A, Hashim I, Berry JD, Das SR, Morrow DA, McGuire DK: Association of troponin $\mathrm{T}$ detected with a highly sensitive assay and cardiac structure and mortality risk in the general population. JAMA 2010; 304:2503-2512.

-12 De Filippi CR, de Lemos JA, Christenson RH, Gottdiener JS, Kop WJ, Zhan M, Seliger SL: Association of serial measures of cardiac troponin $\mathrm{T}$ using a sensitive assay with incident heart failure and cardiovascular mortality in older adults. JAMA 2010;304:2494-2502.
13 Saunders JT, Nambi V, de Lemos JA, Chambless LE, Virani SS, Boerwinkle E, Hoogeveen RC, Liu X, Astor BC, Mosley TH, Folsom AR, Heiss G, Coresh J, Ballantyne CM: Cardiac troponin T measured by a highly sensitive assay predicts coronary heart disease, heart failure, and mortality in the Atherosclerosis Risk in Communities Study. Circulation 2011;123: 1367-1376.

14 Eggers KM, Lagerqvist B, Venge P, Wallentin L, Lindahl B: Persistent cardiac troponin I elevation in stabilized patients after an episode of acute coronary syndrome predicts long-term mortality. Circulation 2007;116:1907-1914.

15 Omland T, Pfeffer MA, Solomon SD, de Lemos JA, Rosjo H, Saltyte Benth J, Maggioni A, Domanski MJ, Rouleau JL, Sabatine MS, Braunwald E: Prognostic value of cardiac troponin I measured with a highly sensitive assay in patients with stable coronary artery disease. J Am Coll Cardiol 2013;61:1240-1249.

16 Alcalai R, Planer D, Culhaoglu A, Osman A, Pollak A, Lotan C: Acute coronary syndrome versus nonspecific troponin elevation: clinical predictors and survival analysis. Arch Intern Med 2007;167:276-281.

17 Tuñón J, Blanco-Colio L, Cristobal C, Tarin N, Higueras J, Huelmos A, Alonso J, Egido J, Asensio D, Lorenzo Ó, Mahíllo-Fernández I, Rodríguez-Artalejo F, Farré J, Martín-Ventura JL, López-Bescós L: Usefulness of a combination of monocyte chemoattractant protein-1, galectin-3, and N-terminal probrain natriuretic peptide to predict cardiovascular events in patients with coronary artery disease. Am J Cardiol 2014;113:434-440.

18 Gomez-Doblas JJ, Muñiz J, Martin JJ, Rodriguez-Roca G, Lobos JM, Awamleh P, Permanyer-Miralda G, Chorro FJ, Anguita M, Roig E: Prevalencia de fibrilación auricular en España. Resultados del estudio OFRECE. Rev Esp Cardiol 2014;67:259-269.

19 Antman EM, Cohen M, Bernink PJ, McCabe CH, Horacek T, Papuchis G, Mautner B, Corbalan R, Radley D, Braunwald E: The TIMI risk score for unstable angina/non-ST elevation MI: a method for prognostication and therapeutic decision making. JAMA 2000; 284:835-842.

20 Eagle KA, Lim MJ, Dabbous OH, Pieper KS, Goldberg RJ, van de Werf F, Goodman SG, Granger CB, Steg PG, Gore JM, Budaj A, Avezum A, Flather MD, Fox KA: A validated prediction model for all forms of acute coronary syndrome: estimating the risk of 6month postdischarge death in an international registry. JAMA 2004;291:2727-2733.

21 Montalescot G, Sechtem U, Achenbach S, Andreotti F, Arden C, Budaj A, Bugiardini R, Crea F, Cuisset T, Di Mario C, Ferreira JR, Gersh BJ, Gitt AK, Hulot JS, Marx N, et al: 2013 ESC guidelines on the management of stable coronary artery disease: the Task Force on the Management of Stable Coronary Artery Disease of the European Society of Cardiology. Eur Heart J 2013;34:2949-3003.

22 Wallace TW, Abdullah SM, Drazner MH, Das SR, Khera A, McGuire DK, Wians F, Sabatine MS, Morrow DA, de Lemos JA: Prevalence and determinants of troponin $\mathrm{T}$ elevation in the general population. Circulation 2006;113: 1958-1965.

23 De Lemos JA: Increasingly sensitive assays for cardiac troponins: a review. JAMA 2013;309: 2262-2269.

24 Eggers KM, Venge P, Lindahl B, Lind L: Cardiac troponin I levels measured with a highsensitive assay increase over time and are strong predictors of mortality in an elderly population. J Am Coll Cardiol 2013;61:1906-1913.

25 Eggers KM, Al-Shakarchi J, Berglund L, Lindahl B, Siegbahn A, Wallentin L, Zethelius B: High-sensitive cardiac troponin $\mathrm{T}$ and its relations to cardiovascular risk factors, morbidity, and mortality in elderly men. Am Heart J 2013;166:541-548.

26 Korosoglou G, Lehrke S, Mueller D, Hosch W, Kauczor HU, Humpert PM, Giannitsis E, Katus HA: Determinants of troponin release in patients with stable coronary artery disease: insights from CT angiography characteristics of atherosclerotic plaque. Heart 2011;97:823-831.

27 Beatty AL, Ku IA, Christenson RH, DeFilippi CR, Schiller NB, Whooley MA: High-sensitivity cardiac troponin $\mathrm{T}$ levels and secondary events in outpatients with coronary heart disease from the Heart and Soul Study. JAMA Intern Med 2013;173:763-769.

28 Omland T, de Lemos JA, Sabatine MS, Christophi CA, Rice MM, Jablonski KA, Tjora S, Domanski MJ, Gersh BJ, Rouleau JL, Pfeffer MA, Braunwald E: A sensitive cardiac troponin $\mathrm{T}$ assay in stable coronary artery disease. N Engl J Med 2009;361:2538-2547.

-29 Wang TJ, Wollert KC, Larson MG, Coglianese E, McCabe EL, Cheng S, Ho JE, Fradley MG, Ghorbani A, Xanthakis V, Kempf T, Benjamin EJ, Levy D, Vasan RS, Januzzi JL: Prognostic utility of novel biomarkers of cardiovascular stress: the Framingham Heart Study. Circulation 2012;26:1596-1604.

-30 Agewall S, Giannitsis E, Jernberg T, Katus H: Troponin elevation in coronary versus noncoronary disease. Eur Heart J 2011;32:404411 .

31 Durante A: The value of elevated high-sensitive troponin T. Am Heart J 2011;161:e33.

32 Wijns W, Crea F: Elevated troponin in stable coronary artery disease: the sound of silence. Heart 2011;97:785-786.

33 Eggers KM, Lagerqvist B, Oldgren J, Venge P, Wallentin L, Lindahl B: Pathophysiologic mechanisms of persistent cardiac troponin I elevation in stabilized patients after an episode of acute coronary syndrome. Am Heart J 2008; 156:588-594. 